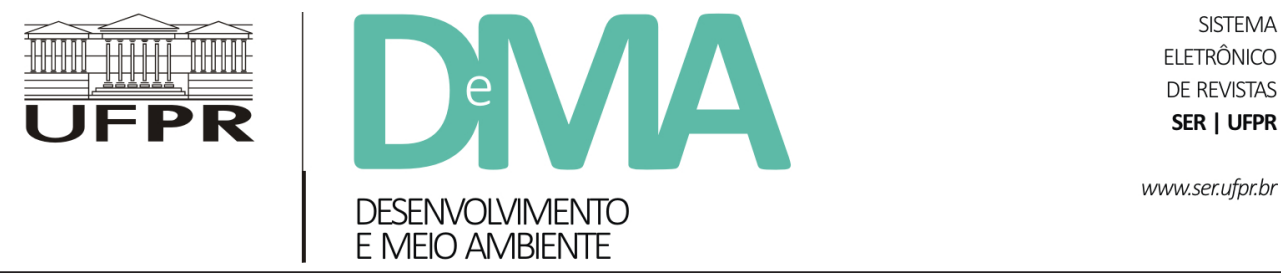

\title{
O papel social da Universidade e o desenvolvimento regional a partir da análise da atuação da UFPR no Litoral Paranaense
}

\section{The Social Role of the University and Regional Development Based on the Analysis of the Activities Carried out by the Federal University of Paraná on the Coastal Region of Paraná}

\author{
Adriana Lucinda de OLIVEIRA ${ }^{1 *}$, Luiz Everson da SILVA ${ }^{1}$, Luiz Alberto ESTEVES ${ }^{2}$ \\ ${ }^{1}$ Universidade Federal do Paraná (UFPR) - Setor Litoral, Matinhos, PR, Brasil. \\ ${ }^{2}$ Universidade Federal do Paraná (UFPR), Curitiba, PR, Brasil. \\ *E-mail de contato: adrilucinda@gmail.com
}

Artigo recebido em 16 de maio de 2016, versão final aceita em 01 de agosto de 2017.

RESUMO: O artigo discute o papel social e contraditório da Universidade, tendo como fundamento teórico a produção gramsciana, com destaque para a relação entre hegemonia, educação e intelectual orgânico, proposta pelo referido autor. As reflexões são circunstanciadas no território do Litoral do Paraná, lócus de atuação de um dos campi da Universidade Federal do Paraná. Na perspectiva de discutir as contribuições dessa instituição no debate de políticas públicas e no desenvolvimento da região, o texto discorre sobre alguns projetos e ações em andamento, bem como elenca demandas e potencialidades identificadas a partir da sistematização da prática docente nessa região, que envolve ensino, pesquisa e programas de extensão. A perspectiva gramsciana subsidia e reforça a necessidade de articulação com os movimentos sociais, a tessitura de uma nova sociabilidade, bem como a construção de práticas educativas emancipatórias.

Palavras-chave: universidade; políticas públicas; litoral do Paraná.

ABSTRACT: In this paper we discuss the social and contradictory role of the University, based on Gramscian production, emphasising the relationship between hegemony, education and organic intellectual proposed by the author. The reflections are centered on the territory of the Coast of Paraná, locus of action of one of the campuses of the Federal University of Paraná. In order to discuss the contributions of this institution in the debate of public policies and in the development of the region, the text presents some projects and actions in progress, as well as demands and potentialities identified from the systematization of the teaching practice in this region, which involves teaching, research and extension programmes. The Gramscian perspective subsidizes and reinforces the need for articulation with social movements, the formation of a new sociability, as well as the construction of emancipatory educational practices. 


\section{Introdução}

O presente texto aborda a Universidade como uma instituição contraditória: historicamente elitizada, meritocrática, a serviço do capital e do Estado burguês -mas também lócus de luta, de resistência, de produção de conhecimento, de desenvolvimento de práticas emancipatórias, espaço da crítica, da proposição, e do compromisso com os interesses populares, colocando a produção de conhecimento, de ciência e tecnologia a serviço da população. O papel social da Universidade, enquanto lócus de formação, é discutido à luz da produção Gramsciana, com destaque para a relação entre hegemonia, educação e intelectual orgânico, proposta pelo referido autor.

Tendo como referência a Universidade Federal do Paraná - Setor Litoral, o presente texto discorre sobre algumas possibilidades de contribuição da Universidade para o seu entorno, tendo como foco as políticas públicas. Para tanto, apresenta uma rápida caracterização da região litorânea do estado do Paraná, e na sequência aborda a UFPR Setor Litoral, evidenciando alguns projetos em andamento, bem como elencando demandas identificadas no cotidiano da docência e do exercício investigativo.

\section{Características do litoral paranaense}

O Litoral do Paraná é composto de sete mu- nicípios: Antonina (968,9771 km2), Guaraqueçaba $(2.159,3374 \mathrm{~km} 2)$, Guaratuba $(1.326,8811 \mathrm{~km} 2)$, Matinhos $(111,5637 \mathrm{~km} 2)$, Morretes $(686,5942$ km2), Paranaguá $(665,8309$ km2) e Pontal do Paraná $(216,2945 \mathrm{~km} 2)$. A área total, que corresponde a $3 \%$ do território paranaense, limita-se ao Norte com o Estado de São Paulo, onde se localiza a Vila de Ararapira, ao Sul com o Estado de Santa Catarina no curso do rio Sahi-Guaçu, a Leste com o Oceano Atlântico e a Oeste com a denominada Serra do Mar. Atualmente, $82 \%$ de sua área está voltada para a conservação, pois possui a maior área contínua de floresta pluvial atlântica preservada (Pierri et al., 2006, p. 150). De acordo com as tipologias propostas pelo Sistema Nacional de Unidades de Conservação, são cinco Unidades de Conservação de Uso Sustentável (uma federal e quatro estaduais), representando $63 \%$ da área total do litoral, e 14 Unidades de Conservação de Proteção Integral (cinco federais, oito estaduais e uma municipal). Além disso, a região conta com treze Reservas Particulares de Patrimônio Natural (RPPN), oito estaduais e cinco federais (Góes, 2014). As RPPN são áreas de reserva ambiental, conhecidas como áreas de reserva de carbono, um dos mecanismos de redução de emissão de gases de efeito estufa.

Apesar da riqueza natural e cultural existente no mosaico de unidades de conservação que permeia esse território, o litoral norte do estado se configura como uma das regiões mais pobres do Paraná, marcada pela sazonalidade e por um desen- 
volvimento lento e dependente da atividade portuária, agrícola e de serviços (turismo).

A sazonalidade é demarcada pela instalação das segundas residências ${ }^{1}$ e de estabelecimentos destinados ao turismo. Durante a temporada, as condições de infraestrutura de serviços básicos, que já são precárias, se deterioram ainda mais, como transporte, saúde, saneamento básico e abastecimento. Somam-se ainda impactos como o ambiental, o aumento dos preços, o trânsito caótico, violência e altos níveis de poluição sonora. Passado o período da temporada de verão, a região sofre uma depressão de suas atividades econômicas e parte de toda a estrutura de segundas residências fica subutilizada.

A vulnerabilidade econômica da população expressa o contraditório e excludente processo de acumulação capitalista no Litoral do Paraná, haja vista sua riqueza natural, diversidade cultural dada pela presença de indígenas, quilombolas, ribeirinhos, caiçaras e pequenos agricultores, e ainda pelo fato de ter em seu território, desde 1935, um dos principais portos do país, por onde escoa a suntuosa produção do agronegócio nacional.

Por muito tempo, o papel do litoral ficou praticamente reduzido à sua função portuária, servindo para escoar os produtos das regiões privilegiadas pelo capital para o exterior. Paralelamente, constituiu-se o uso pesqueiro, mas esse uso sempre foi secundário em relação ao portuário e nunca teve relevância para o desenvolvimento econômico do Paraná. Só nas últimas décadas do século XX o litoral constituiu-se, também, num espaço de investimento turístico, oferecendo oportunidades de descanso e lazer, majoritariamente a curitibanos de classe média e, em menor grau, a pessoas do interior do Estado da mesma condição social. Esse perfil turístico configurou o uso balneário dos municípios praianos. Finalmente, a grande extensão de natureza preservada do litoral paranaense, de valor ambiental mais que econômico, propiciou, no contexto político contemporâneo de preocupação pela proteção da natureza e da biodiversidade, a construção da maior parte de seu território em áreas de conservação (Pierri et al., 2006, p. 137-167).

A realidade da região se complexificou nos últimos anos dada a necessidade de ampliação da distribuição de mercadorias via porto, e da identificação por parte das grandes empresas da localização privilegiada do litoral. Esse processo tem sido fruto de vários embates entre ambientalistas e representantes do grande capital em torno de várias obras, como a ampliação do porto de Paranaguá, a criação do porto de Pontal do Paraná ${ }^{2}$, a construção de polidutos, a criação da ferrovia e a ampliação da malha ferroviária e rodoviária. Presencia-se na região uma contradição constante marcada por interesses do grande capital - que historicamente demarcam uma relação utilitária com esse território - e as demandas e necessidades da população local, que vive os im-

\footnotetext{
${ }^{1}$ Segunda residência pode ser definida como um alojamento particular, com fins associados ao lazer e ao descanso, usados de forma temporária por pessoas que possuem residência fixa em outro lugar. Registra-se que o IBGE, nos censos de 1991, 2000 e 2010, classificou as segundas residências para fim de tipificar os domicílios brasileiros em “domicílios particulares de uso ocasional” (Esteves, 2011, p.68).

${ }^{2}$ Segundo Góes (2014), Pontal do Paraná está numa localização estratégica, chamando a atenção de grandes empreendedores, pois possui um calado natural por estar localizado na entrada da baía de Paranaguá, permitindo a atracagem de navios de maior porte.
} 
pactos do atual estágio da acumulação capitalista, expressos nas ameaças ambientais, na desregulamentação dos direitos trabalhistas, na sazonalidade do mercado de trabalho, no turismo predatório e na histórica cultura política clientelista e patrimonialista da região.

Esse cenário compôs as justificativas do processo de expansão e interiorização da Universidade Federal do Paraná - UFPR, com a criação do Setor Litoral.

\section{A UFPR - Setor Litoral}

A implantação do Setor Litoral da UFPR, no ano de 2004, foi fruto da negociação entre a Universidade Federal do Paraná, o governo do Estado do Paraná, a Prefeitura de Matinhos, a Secretaria de Estado da Ciência, Tecnologia e Ensino Superior, o Centro Federal de Educação Tecnológica do Paraná (CEFET) e a Faculdade Estadual de Filosofia, Ciências e Letras de Paranaguá (FAFIPAR - UNESPAR), que em 2001 firmaram um termo de cooperação para a implantação de ações para ampliação do acesso à educação na região.

A conjuntura política da época também interferiu para a concretização de ações de ampliação do Ensino Superior. Em 2002, ocorreu a eleição do Presidente Luiz Inácio Lula da Silva e do governador do Estado do Paraná, Roberto Requião. Ambos tinham em suas plataformas de governo o compromisso com a ampliação do acesso ao Ensino Superior, com ênfase nas regiões mais afastadas dos grandes centros urbanos. Da mesma forma, a gestão 2002-2006 da UFPR teve a expansão como um de seus objetivos.

A proposta de criação de uma expansão da UFPR no litoral do Paraná esteve, desde o princípio, muito vinculada ao debate sobre o desenvolvimento da região, dado seus baixos índices de IDH, turismo sazonal e a sua riqueza ambiental.

Frente a essa conjuntura, os idealizadores propuseram um projeto político-pedagógico (PPP) diferente dos demais setores da UFPR, caracterizado pelo seu desenho curricular, formas de avaliação, estratégia de gestão, fundamento teórico-filosófico e relação com estudantes e comunidade. A concepção político-pedagógica explicitada no PPP da UFPR Litoral assume o desafio de exercitar seu papel social de agente de transformação, de questionador crítico e fomentador de conhecimentos que dialoguem e interfiram na realidade social, para além das exigências do capital. Assume, também, uma concepção ampliada de educação como um processo de socialização e aprendizado que perpassa todas as dimensões da vida, conduz a experiências, exercícios e vivências de libertação, humanização, conscientização - delineando outro modus operandi, o qual potencializa a capacidade de ser no mundo, valorizando a criatividade, a autonomia e as dimensões coletiva e humana.

Desta forma, o Setor Litoral da UFPR foi criado para ser uma potencialidade da região, um estímulo, uma estratégia para contribuir na construção de alternativas de desenvolvimento mais sustentáveis para esse território.

\section{Universidade e desenvolvimento}

Parte-se do pressuposto que conceber desenvolvimento com sustentabilidade ambiental e econômica nos marcos do capitalismo são "coisas" incompatíveis. O modelo de desenvolvimento em 
voga no cenário brasileiro, denominado de novo desenvolvimentismo ${ }^{3}$, acopla uma agenda social ao projeto neoliberal, promovendo o sincretismo de medidas de estímulo a intervenções pontuais e focalizadas do Estado e do Terceiro Setor nas expressões mais agudas da questão social, reconhecendo as falhas do mercado sem, no entanto, discutir ou tocar nos fundamentos da vida mercantil generalizada no capitalismo ou no metabolismo do capital (Castelo, 2012).

Esse modelo de desenvolvimento fundamenta-se nas diretrizes dos organismos internacionais como: FMI, OCDE, UNESCO, Banco Mundial, BIRD e na CEPAL que compreende um pacote de medidas, tais como: intervenção estatal na economia e na questão social para estimular crescimento e distribuição de renda, política externa mais ativa, investimentos em infraestrutura, redução gradual dos juros, aumento do crédito ao consumidor e do salário mínimo, desonerações fiscais e tributárias, e financiamento do capital monopolista nacional via Banco Nacional de Desenvolvimento Econômico e Social (Castelo, 2013, pg. 123 e 130).

Ideológica e politicamente, o novo desenvolvimentismo tem como estratégia a pedagogia da hegemonia, que busca assegurar que a dominação de classes se viabilize através de processos educativos "positivos", enaltecendo a importância da participação de cada cidadão na mudança política e na definição de formas alternativas de ações sociais, com vistas à coesão social. Caracteriza-se por um realinhamento ideológico, teórico e político na construção de consenso e da repolitização da política com predomínio da pequena política em detrimento da grande política (Coutinho, 2010), ou seja, pela emergência de questões específicas (micro) no lugar de análises ampliadas (macro). Esse processo reduz os níveis de consciência política coletiva das várias frações da classe trabalhadora, impulsiona seus intelectuais coletivos a pautarem suas agendas políticas por demandas que, embora realizem mudanças parciais nas condições de trabalho e de vida das classes dominadas, mantêm praticamente inalteradas as relações de exploração e de expropriação concernentes às relações sociais capitalistas (Martins \& Neves, 2010, p. 37).

Assim, o padrão de acumulação capitalista dependente vem sendo aprofundado com alto grau de consentimento popular, a despeito da persistência de selvagens desigualdades, da violência da expropriação de terras e direitos sociais e da erosão das políticas universalistas (Leher, 2010, p.12).

Os defensores do novo desenvolvimentismo atribuem a pobreza, a superexploração do trabalho e as desigualdades sociais às falhas do mercado e a não dotação de certos ativos por parte dos pobres. Já para os pesquisadores alinhados com a perspectiva crítica marxista, essas expressões da questão social são atribuídas à dinâmica da acumulação capitalista e à inserção subordinada do Brasil no mercado mundial (Castelo, 2012).

Tendo como pressuposto uma perspectiva crí-

\footnotetext{
${ }^{3} \mathrm{O}$ novo desenvolvimentismo é uma corrente contemporânea do pensamento brasileiro que nasce na esteira do nacional-desenvolvimentismo, que orientou a economia dos países subdesenvolvidos, no período de 1940-1970, sob a orientação da Comissão Econômica para a América Latina e Caribe (CEPAL). Tinha como características: (1) a defesa da autonomia e da soberania nacionais; (2) a industrialização como meio necessário para a superação dos entraves ao desenvolvimento da periferia; (3) o Estado entendido como um agente estratégico promotor de políticas de planejamento e bem-estar social; e (4) a participação ativa de uma intelligentsia culta e bem formada na gerência de postos-chave do Estado (Castelo, 2009, pg.73).
} 
tica de desenvolvimento e do papel social da Universidade, considera-se que esta, enquanto espaço contraditório, pode constituir-se em lócus de formação de intelectuais orgânicos, em espaço de crítica, de proposição, de compromisso com os interesses populares, colocando a produção de conhecimento, a ciência e a tecnologia a serviço da população.

Nesse processo, defende-se que do interior da Universidade pode surgir ações e sujeitos que desenvolvam a mediação, a articulação e a mobilização virtuosa das potencialidades regionais através da organização da cadeia produtiva, do aporte tecnológico, do desenvolvimento de pesquisa em parceria com as outras IES, do fortalecimento da educação superior com a educação básica e tecnológica, da proposição de políticas de geração de trabalho e renda, do suporte na qualificação e principalmente da articulação com os movimentos sociais.

\section{A universidade como espaço contraditório e a contribuição Gramsciana}

Os desafios postos à Universidade, na perspectiva de desenvolver o seu papel social, demandam a clareza do projeto defendido de educação, de sociedade e de Universidade para trilhar cada passo com persistência, clareza política e paciência histórica. Gramsci aponta que esse desafio requer:

1) Não se cansar jamais de repetir os próprios argumentos (variando literalmente a sua forma): a repetição é o meio didático mais eficaz para agir sobre a mentalidade popular; 2) trabalhar de modo incessante para elevar intelectualmente camadas populares cada vez mais vastas, isto é, para dar personalidade ao amorfo elemento de massa, o que significa trabalhar na criação de elites de intelectuais de novo tipo, que surjam diretamente da massa e que permaneçam em contato com ela para se tornarem seus 'espartilhos'(1999, p. 110).

A proposta de Gramsci convida todos à mobilização popular, e a um trabalho orgânico com os movimentos sociais e com a população. Reitera-se a necessidade da Universidade fortalecer, intramuros, uma educação emancipatória e, extramuros, uma articulação e comprometimento com as demandas do seu entorno.

A obra gramsciana colabora para a discussão das determinações sociais, intelectuais e políticas do real no plano da totalidade, ou seja, para uma crítica ontológica a partir das outras esferas do ser social que não a estritamente econômica, possibilitando trazer para a cena o debate sobre a cultura como lógica interna que parametriza as manifestações do capitalismo neste estágio globalizado. Assim, a construção de um outro projeto de sociedade e de educação demanda, acima de tudo, um outro modo de pensar, a revisão de valores e concepções, a análise histórica dos fatos e suas determinações, a práxis política e o entendimento da noção de hegemonia para a construção da contra-hegemonia. A obra de Gramsci estabelece a relação entre hegemonia, educação e intelectual.

Para Gramsci, a hegemonia caracteriza-se pela "supremacia de um grupo social que se manifesta de dois modos, como ‘domínio’ e como ‘direção intelectual e moral'. Um grupo social domina os grupos adversários, que visa a 'liquidar' ou a submeter inclusive com a força armada, e dirige os grupos afins e aliados" (Gramsci, 2002, p.62).

As discussões sobre acumulação capitalista, educação e Universidade, alinhadas às demandas do capital, evidenciam que, na sociedade capitalista, a hegemonia tem sido dos detentores do capital. 
Simionatto (2014) atualiza essa discussão ao afirmar que, na contemporaneidade, a hegemonia burguesa é sustentada pelo trabalho dos intelectuais a serviço do poder, alinhando ideias e instrumentos de controle e disseminação de ideologia nos campos social, político, econômico e cultural. Para exemplificar, a autora cita os governos de Thatcher e Reagan, fundamentados na produção de Friedrich Hayek sobre o liberalismo, e na Terceira via de Clinton e Blair, alicerçadas na produção de Anthony Giddens.

Para Eagleton (1997), a hegemonia não é apenas um tipo de ideologia, mas abarca as várias dimensões da vida coletiva, como a econômica, política, cultural, educacional e ideológica. Constitui a materialização do poder de um grupo social dominante através de um sistema de significação.

Assim, a hegemonia compreende um sistema que envolve cada sujeito por todos os lados, através de todos os espaços de socialização, desde instituições como família, escola, igreja, exército, sindicato, como através da cultura que vai sendo incorporada, dia após dia, e vai tecendo um conjunto de ideias, concepções de justiça e juízos de valor.

A hegemonia é historicamente construída, por isso não é algo estático, mas mantido, renovado ou modificado pelos sujeitos que dão vida às instituições. Segundo Gramsci (2006), as principais instituições educativas e organizadoras da cultura são a escola e a igreja, além dos meios de comunicação de massa.

Para Gramsci (2006), são essas instituições que compõem a sociedade civil, ao lado do Estado como sociedade política, que exerce a função educativa e sustenta a hegemonia. Contudo, a relação pedagógica não deve ser limitada às relações escolares, enquanto espaço privilegiado de aprendiza- do. Essa relação perpassa toda a sociedade no seu conjunto e todo indivíduo nas suas relações com os outros, intelectuais e não intelectuais, dirigentes e dirigidos, governantes e governados. Toda relação de hegemonia é por si só uma relação pedagógica.

Nessa perspectiva, a função educativa pertence aos intelectuais que atuam em diversos espaços da sociedade. Esses difundem a concepção de mundo do grupo social ao qual estão ideologicamente alinhados. Assim, o grupo dominante mantém a hegemonia através dessas instituições e dos meios de comunicação de massa, amparado pelos intelectuais que ele próprio criou e pelos intelectuais oriundos dos grupos dominados que assimilaram a sua concepção de mundo (Marçal, 2011).

Nesse sentido, quando a Universidade é concebida como espaço contraditório, a obra de Gramsci é um importante fundamento teórico, na medida em que no interior dessa instituição possa haver grupos que questionem a direção hegemônica e que estejam dispostos a compor a construção de uma contra-hegemonia. Por isso, a importância da contribuição de Gramsci também na abordagem sobre os intelectuais. O referido autor afirma que sem a ação dos sujeitos é impossível se fazer história, é impossível fazer com que o conhecimento seja uma arma de transformação. Valoriza assim cada homem e mulher no processo de transformação da realidade, considerando que cada pessoa no seu modo de pensar expressa uma visão de mundo, já que "todos os homens são intelectuais, mas nem todos os homens têm na sociedade a função de intelectuais" (Gramsci, 2006, p. 18).

A importância de todos os sujeitos para o processo de transformação está presente nos debates que envolvem a busca de alternativas ao capitalismo, assim como a necessidade de politização, auto- 
nomia, emancipação e dignidade. Um mundo mais humano não ocorrerá sem atores organizados, luta política e a tessitura de um outro imaginário social. A construção de sujeitos políticos é também a construção de uma contra-hegemonia, de uma outra cultura. Segundo Gramsci, o processo de produção dos intelectuais orgânicos ${ }^{4}$ é

longo, difícil, cheio de contradições, de avanços e de recuos, de debandadas e reagrupamentos e está ligado ao próprio desenvolvimento cultural do grupo social (...) autociencia crítica significa, histórica e politicamente, criação de uma elite de intelectuais: uma massa humana não se 'distingue' e não se torna independente 'para si' sem organizar-se (...) e não existe organização sem intelectuais, isto é, sem organizadores e dirigentes (Gramsci, 2006, p. 104).

Gramsci acredita que a escola pode ser transformadora de uma sociedade à medida que proporciona às classes meios para uma organização e meios de governar. Pode trazer ainda um esclarecimento que contribui para a elevação cultural das massas.

O autor faz uma crítica à organização escolar de sua época e defende a escola única inicial de cultura geral, humanista e formativa, que equilibre de modo justo o desenvolvimento da capacidade de trabalhar manualmente (tecnicamente e industrialmente) e o desenvolvimento das capacidades de trabalho intelectual.

A preocupação de Gramsci está em torno da formação a que todos deveriam ter acesso: a escola deveria proporcionar aos jovens uma autonomia na orientação e na iniciativa, pois concebe o processo educacional como potencializador de construção de mudanças, de autonomia e de liberdade.

Assim como existe a necessidade de manutenção da hegemonia pelo grupo dominante, existe a possibilidade também de construir a contra-hegemonia pelos grupos subalternos em uma sociedade. Para Gramsci, a construção de uma contra-hegemonia pode se iniciar também no terreno cultural e educacional, a partir da organização e sistematização de uma concepção de mundo coerente e própria dos grupos subalternos.

Nessa perspectiva, a produção de Gramsci ancora e subsidia uma discussão e a tentativa de construir atividades educativas emancipatórias (Tonet, 2014), a partir da atuação de grupos contra-hegemônicos que estão na Universidade.

Diante desse escopo, reforça-se a necessidade de articulação de vários atores sociais, de pensar e conceber a complexidade das dimensões da vida, de nutrir a irreverência, de acreditar no poder e no saber de cada homem e mulher. Construir processos emancipatórios, transformadores e libertários caracteriza-se no caminho a trilhar, almejando-se um mundo mais humano, equânime e democrático.

Assim, a partir de um movimento de aproximações sucessivas da realidade social do litoral do Paraná e da atuação da UFPR, algumas ações e proposições são elencadas no campo das políticas públicas, espaço de discussão e de disputa, que carece de interlocutores capacitados para o controle

${ }^{4}$ Para Gramsci, a organicidade de pensamento e a solidez cultural só poderiam ocorrer se entre os intelectuais e os simples se verificasse a mesma unidade que deve existir entre teoria e prática, isto é, se os intelectuais tivessem sido organicamente os intelectuais daquelas massas, ou seja, se tivessem elaborado e tornado coerentes os princípios e os problemas que aquelas massas colocavam com a sua atividade prática, constituindo assim um bloco cultural e social (Gramsci, 1999). 
social, gestão, participação dos usuários, monitoramento e avaliação.

\section{Universidade e políticas públicas}

Ao abordar as políticas públicas no contexto do capitalismo contemporâneo, adentra-se num dos pontos mais sensíveis e problemáticos da nossa realidade social e individual. Os direitos sociais estão imersos numa cultura política dominada pelo patrimonialismo e seletividade. O percorrer deste caminho possibilita situar a emergência das políticas públicas no contexto do desenvolvimento capitalista e do Estado liberal, passando pelos vários momentos sociopolíticos que marcaram o século XX no Brasil até o momento em que os direitos sociais, reconhecidos de maneira sem igual em nossa história, estão sendo asfixiados em nome da governabilidade e modernização do Estado por meio da quase total desconsideração dos problemas de desigualdade social.

Compreender a formação das políticas públicas implica no esforço de situá-las no contexto de desenvolvimento do Estado de perspectiva liberal e das relações capitalistas de produção. As significativas modificações que estes acontecimentos provocaram no âmbito das relações societárias determinaram a emergência de novas necessidades sociais e novos impasses, ou seja, essa conjuntura explicitou sob diferenciadas formas a chamada "questão social", a qual se tornou base para outras maneiras de intervenção.

As políticas públicas constituem-se em instrumento redistributivo, que cumpre funções políticas e econômicas e pode funcionar como mecanismo de legitimação da ordem. Portanto, cabe compreender as políticas públicas a partir de seus entrelaçamentos contraditórios que articulam processos econômicos, políticos, institucionais, sociais e jurídicos visando ao consenso social, à aceitação e legitimação da ordem, à mobilização/desmobilização da população, à manutenção das relações sociais, à redução de conflitos, entre outros. O que na atualidade tem recebido a denominação de políticas públicas resume-se, na maioria das vezes, em programas tópicos dirigidos a determinados grupos focalizados, descontínuos, seletivos, com atuação dispersa, sem planejamento, avaliação nem controle da sociedade (Vieira, 2007).

As políticas têm como alvo as seqüelas da questão social e cumprem uma função social de prestar serviços sociais e assistenciais, outorgando um "complemento" salarial às populações carentes. Para Saraiva, a política pública é compreendida como

Um sistema de decisões públicas que visa a ações ou omissões, preventivas ou corretivas, destinadas a manter ou modificar a realidade de um ou vários setores da vida social, por meio da definição de objetivos e estratégias de atuação e da alocação dos recursos necessários para atingir os objetivos estabelecidos (Saraiva, 2006, p. 29).

Segundo Pastorini (1997), o Estado capitalista, por meio das políticas públicas, contribui para o barateamento da força de trabalho, mediante a socialização dos custos da sua reprodução. Desta forma também contribui para a fragmentação da "questão social", que é pensada de forma parcializada, o que determina que a política social seja transformada em "políticas sociais", destinadas a atender problemáticas particulares e específicas.

Outro equívoco do desenho das políticas públi- 
cas no Brasil tem sido a limitação a públicos-alvos ou demandas genéricas, sem uma análise das diferenciadas realidades concretas dos territórios.

A importância do território em suas múltiplas dimensões reside em considerá-lo, em sua essência, como o chão concreto das políticas, raiz dos números e a realidade da vida coletiva, que representa de forma proativa a base do exercício da cidadania e fundamenta as relações sociais de vizinhança e de poder, visto que esse território também é um fator dinâmico no processo de exclusão/inclusão social em que as desigualdades sociais se evidenciam (Koga, 2011). Nessa perspectiva, mesmo que tenhamos desenhos de políticas públicas genéricas e de amplo espectro, há que voltar-se para as especificidades e características de cada região, como estratégia de otimizar e ir ao encontro das peculiaridades e vicissitudes de cada território.

\section{Ações da UFPR Setor Litoral em um contexto regional}

Partindo das especificidades do litoral paranaense, território de desafios e potencialidades, destacam-se as populações que o compõem com suas riquezas, peculiaridades e diversidade. São quilombolas, ribeirinhos, pescadores, caiçaras, indígenas, pequenos agricultores, artesãos, pequenos e médios empreendedores que convivem com a mistura entre a vida pacata das cidades e os interesses do grande capital expresso nos investimentos internacionais, que prometem uma melhoria de vida à população por meio da geração de novos postos de trabalho e do crescimento econômico. Exemplo disso é o município de Pontal do Paraná, onde está instalada a multinacional italiana Techint, que atua no ramo de construção de plataformas de petróleo. Três outras empresas estão na fase de análise de Licenciamento Ambiental para instalação: Terminal de Contêineres de Pontal do Paraná - TCPP, Subsea 7 e Odebrecht.

Esses grandes empreendimentos ${ }^{5}$ expressam a voracidade do processo de acumulação capitalista em uma região caracterizada por ainda conter uma reserva expressiva de mata atlântica. Vale esclarecer que, mesmo com esse interesse especial para a conservação da biodiversidade, com aproximadamente $80 \%$ de seu território dentro de áreas protegidas legalmente, mais de $60 \%$ são áreas de uso sustentável que não impedem a instalação de empreendimentos de infraestrutura (Góes, 2014).

Nessa perspectiva, o debate sobre a política ambiental é uma demanda efetiva para a UFPR Setor Litoral, que, diante desses empreendimentos, tem mostrado suas contradições e disputas internas. Há a coexistência de grupos que identificam nesses empreendimentos um risco ambiental e poucas melhorias para a qualidade de vida da população e outros que visualizam a chegada do desenvolvimento econômico na região e a geração de muitos postos de trabalho. Zhouri \& Laschefski (2010), ao analisarem as obras advindas do Plano de Aceleração do Crescimento (PAC), afirmaram que grandes projetos de infraestrutura foram retomados, como hidrelétricas, hidrovias, rodovias, portos, entre outros, ao longo dos antigos eixos de desenvolvimento, desta vez com a perspectiva da "inclusão internacional" da nação no mercado global. Denominam esse

${ }^{5}$ Goés (2014) realizou recentemente um levantamento desses empreendimentos de infraestrutura na região, que se executados, irão a curto prazo redefinir a realidade desse território demograficamente, economicamente, politicamente e principalmente ambientalmente. 
processo de "paradigma da adequação ambiental" ou "esverdeamento do empresariado", haja vista o empenho em garantir ações de mitigação e compensação ambiental. Apesar disso e dos avanços sociais, os resultados desse modelo de desenvolvimento sustentável baseado na chamada modernização ecológica não são animadores no seu conjunto. Os índices que apontam para as mudanças climáticas estão cada vez mais evidentes, o desmatamento continuou dentro das mesmas taxas anuais, a extinção de espécies se acelerou, o quadro de poluição do solo, da água e do ar se agravou e a desigualdade social, apesar dos avanços nas políticas de inclusão social, não diminuiu. Na última década, vimos ressurgir no Brasil velhos conflitos em torno da temática socioambiental.

Diante desse cenário, a pesquisa, a reflexão crítica, o olhar investigativo em diferentes escalas se faz premente, bem como o compromisso com a construção de um projeto de sociedade e de Universidade que tenha como prioridade a qualidade de vida da maioria da população e a sustentabilidade ambiental. Nesse sentido, aos grupos do interior da Universidade alinhados com a defesa dos recursos naturais, coloca-se o desafio de monitorar as ações realizadas, contribuir com os movimentos sociais para a garantia de voz às populações tradicionais, bem como para a garantia de ações efetivas de compensação e mitigação ${ }^{6}$ da implantação de empreendimentos de infraestrutura.

Referente às populações tradicionais, destacam-se os ribeirinhos, que têm sofrido cerceamento da sua atividade de subsistência devido à legislação direcionada aos barcos pesqueiros de grande porte. Os ribeirinhos são pescadores de pequeno porte, catadores de crustáceos e moluscos, que têm nessa atividade sua fonte de renda de modo precário e desprotegido, principalmente pela sazonalidade e pelos impactos ambientais sofridos pela degradação do ecossistema.

Historicamente, as diretrizes políticas e econômicas para o setor pesqueiro brasileiro fomentaram e privilegiaram o agronegócio da pesca oceânica e da aquicultura, provocando sobre-exploração dos estoques e danos ambientais. Essas políticas não têm contemplado as necessidades dos trabalhadores e trabalhadoras, bem como não reconhecem as atividades provenientes da cadeia produtiva da pesca que compreende não somente a pesca em si, mas o beneficiamento do pescado, a confecção de artesanato e o manejo na aquicultura e piscicultura (Silva et al., 2014).

O Grupo Integrado de Aquicultura e Estudos Ambientais da Universidade Federal do Paraná desenvolve, desde 2005, o Projeto Cultimar, no município de Guaratuba. O projeto surgiu da necessidade de criação de novas fontes de renda para comunidades tradicionais da região litorânea, de forma sustentável e que não descaracterizasse o ambiente natural ou as atividades tradicionais dessas áreas.

Assim, o projeto desenvolve apoio e assessoria a comunidades para a geração de renda a partir da maricultura, bem como ações de educação ambien-

\footnotetext{
${ }^{6}$ A compensação ambiental é um instrumento de política pública que, intervindo junto aos agentes econômicos, proporciona a incorporação dos custos sociais e ambientais da degradação gerada por determinados empreendimentos em seus custos globais. Já as ações de mitigação compreendem estratégias de diminuição da degradação/ impacto ambiental.
} 
tal, valorização da cultura local, capacitação técnica para a otimização da atividade quanto ao cultivo, manejo, beneficiamento e comercialização da produção. Atualmente o projeto tem como foco o apoio no desenvolvimento da cadeia produtiva da ostra nativa (Cultimar, 2015)

Ao conhecer o Projeto Cultimar, identifica-se a potencialidade de um trabalho mais integrado entre o Setor Litoral e o Grupo de Estudos proveniente do Setor de Ciências Agrárias no sentido de otimizar e ampliar a atuação com essas comunidades para os demais municípios do litoral.

Intrinsecamente articulada com a política ambiental, a política urbana também sofre impactos e requer discussão diante das conquistas do direito à cidade, tão pouco difundido entre a população. Perpassam por essa política as demandas relacionadas às necessidades habitacionais, saneamento básico, instalação e distribuição de equipamentos sociais no território, bem como análise de acessibilidade, mobilidade, trânsito e planejamento urbano.

Tendo como marco a catástrofe ambiental de março de 2011, um grupo de professores/as, técnicos e discentes iniciou um trabalho de intervenção social, com vistas à mobilização e organização da população atingida pelas águas de março. Desse trabalho enredaram-se uma série de projetos e ações todos voltados a políticas públicas, com ênfase nas demandas e necessidades sociais das populações (rural e urbana) afetadas nas enchentes de 2011, entre esses: Programa de Desenvolvimento Urbano e Regional, Observatório de Geotecnologias Sociais Regional, Intervenção em Áreas de Habitações Precárias para Inclusão Social.

A ação extensionista compreende três eixos estruturantes: direito à inclusão, políticas públicas e planejamento territorial local, tendo como elemen- tos centrais a produção habitacional sustentável e o projeto técnico social para a inclusão produtiva através dos programas do governo federal em torno da discussão da Política Nacional de Habitação de Interesse Social.

A utilização de geotecnologias e do estudo socioambiental têm sido as principais estratégias utilizadas para construir com a população um processo de levantamento de demandas habitacionais de interesse social, objetivando a formulação de planos e programas de políticas públicas locais mais específicas na área do desenvolvimento territorial e regional.

Esse processo tem gerado a discussão sobre o uso da nova cartografia social do litoral paranaense como instrumento de planejamento urbano e regional, através da produção cartográfica, treinamento, capacitação, coleta e preparação de dados geográficos e impressão de mapas.

Através da publicização da ferramenta do georreferenciamento, o grupo de trabalho tem buscado envolver e capacitar agentes públicos, sociais e lideranças dos movimentos sociais para formulação de planejamento territorial, desenvolvimento social, uso e ocupação do solo de forma sustentável. Assim, a visualização cartográfica tem sido um recurso fundamental, pois sistematiza e explicita os equipamentos sociais existentes, os direitos básicos não acessados e as demandas e potencialidades de cada território.

Esse trabalho gerou, entre outros frutos, o termo de cooperação técnica entre a UFPR Setor Litoral e a Prefeitura Municipal de Matinhos para a execução do projeto SIG Matinhos - Sistema de Informações Geográficas para a gestão municipal. No momento, o Observatório de Geotecnologias Sociais Regional reúne todas essas ações e repre- 
senta uma ação orgânica de produção de tecnologia social a serviço da população.

Outro programa que tem desenvolvido um trabalho sistematizado é o Laboratório Móvel de Educação Científica do Setor Litoral, que desde 2006 vem integrando pesquisa, extensão e educação científica na região através de um trabalho orgânico com as escolas municipais e estaduais da região. Tem atuado na produção de conhecimento sobre ambientes e culturas regionais e sobre metodologias de trabalho e recursos didáticos que buscam o desenvolvimento de atitudes, habilidades e conhecimentos científicos, desmistificando o fazer científico. O objetivo maior do programa é a popularização e a aplicação prática da ciência, numa perspectiva de ciência e tecnologia a serviço da comunidade. Para tanto tem formado, em parceria com as escolas, clubes de ciências que têm como objetivo central "desenvolver nos estudantes um espírito investigativo, estimulando a utilização do método científico a partir de situações reais" (LABMÓVEL, 2014, p. 4). Já realizou também quatro Feiras de Ciências, objetivando a divulgação e difusão do conhecimento e da iniciação a pesquisa de crianças e adolescentes, que, através de experimentos fora do ambiente da sala de aula, vão exercitando o olhar investigativo, a curiosidade científica, a capacidade de análise, de resolução de problemas práticos e principalmente experimentando a aplicação dos saberes cientificamente construídos, dando-os significado e materialidade. Com esses mesmos objetivos, o LabMóvel tem realizado desde 2011 as Feiras Regionais de Ciências. As feiras têm sido anuais e são o momento de divulgação de maior espectro da produção das escolas. Esse trabalho é fundamentado em atividades de pesquisa em diversas áreas, como: educação e divulgação científica, agrotóxicos no litoral para- naense, biodiversidade da mata atlântica, qualidade do ar e da saúde no município de Paranaguá. Compõem ainda as atividades do LabMóvel as mostras científicas itinerantes, que têm como objetivo o acesso aos saberes locais numa perspectiva de educação para a sustentabilidade; o meliponário didático-científico; a produção de mídias interativas e a produção de materiais pedagógicos, didáticos e científicos. O programa LabMóvel tem procurado ampliar as ações, através das parcerias com as escolas e com o núcleo regional de educação, e tem buscado financiamento nos editais relacionados a políticas públicas para a popularização da ciência.

Além das demandas e das ações desenvolvidas nas políticas ambientais, urbanas e de popularização da ciência, identifica-se a inexistência de um desenho articulado entre as políticas de educação e trabalho/emprego, no sentido de atender as demandas e potencialidades da população local. Nesse sentido, visualiza-se que uma das possibilidades é a construção de um plano de fixação de mão de obra, que compreenda pesquisa e monitoramento das demandas de formação da população, bem como uma ampla divulgação das potencialidades e especificidades dos egressos do setor litoral. Alguns cursos, dado seu ineditismo, não possuem ainda uma identidade profissional estabelecida e, por conseguinte, não são demandados pelo mercado de trabalho. Pode-se exemplificar isso por meio dos egressos dos cursos de Gestão e Empreendedorismo, Gestão Ambiental, Gestão Desportiva e do Lazer, Tecnologia em Agroecologia, Gestão Imobiliária, Gestão Pública, Gestão de Turismo e Informática e Cidadania. Uma estratégia para concretização desse plano pode ser um projeto de parceria entre os entes federativos e representantes dos trabalhadores. As experiências de propostas submetidas ao Instituto Nacional de 
Estudos e Pesquisas Educacionais Anísio Teixeira (INEP) podem ser exemplos de projetos que envolveram bolsas de recém-formados e recursos para infraestrutura de laboratórios.

A existência de outras instituições de ensino superior públicas caracteriza-se também em uma potencialidade, na medida em que projetos em conjunto possam vir a ser elaborados. A região conta com o Instituto Federal do Paraná - Campus Paranaguá, Universidade Estadual do Paraná - Campus Paranaguá e com a UFPR Setor Litoral e o Centro de Estudos do Mar. A construção de um grupo de pesquisa interinstitucional tem a potencialidade de agregar e otimizar os recursos disponíveis nas instituições, bem como propor ações em parceria com os demais atores sociais. Dessa possível articulação podem surgir núcleos de inovação tecnológica, com vistas a atender as demandas dos empreendedores da região.

O Programa de Mestrado em Desenvolvimento Territorial Sustentável é uma potencialidade nesse sentido, pois por meio de suas três linhas de pesquisa (Socioeconomia e Saberes Locais, Redes Sociais e Políticas Públicas e Ecologia e Biodiversidade) tem buscado discutir a indissociabilidade entre natureza, cultura e sociedade numa perspectiva interdisciplinar, bem como tem assumido o desafio de pensar o ecodesenvolvimento por meio da realidade local e/ou regional. Entre as iniciativas em andamento do programa, destaca-se o grupo de pesquisa em biodiversidade e educação do litoral do Paraná (GEPEBELP), que possui uma cooperação com a Embrapa Alimentos do Rio de Janeiro - RJ, Embrapa Recursos Genéticos e Biotecnologia de Brasília - DF, Instituto Paranaense de Assistência Técnica e Extensão Rural - EMATER - PR, Universidade Regional de Blumenau - FURB,
Instituto Federal do Paraná - Campus Paranaguá e com o Instituto Chico Mendes de Conservação da Biodiversidade (ICMBio).

O grupo GEPEBELP compõe a REBIFLORA - Rede de Bioprospecção e Inovação da Floresta Atlântica, por meio dessa cooperação, tem atuado no resgate dos saberes etnobotânicos, na construção de protocolos de propagação das espécies nativas da Floresta Atlântica do litoral paranaense e no manejo e/ou cultivo, por produtores e comunidades tradicionais, de recursos genéticos da floresta que possam ser utilizados como fonte medicinal e/ ou tecnológica e, consequentemente, agregadores de valor econômico ao ecossistema da região. A utilização de substâncias extraídas de plantas tem sido divulgada por vários pesquisadores como uma ferramenta viável na busca de novas entidades terapêuticas. As espécies vegetais nativas do litoral do Paraná podem, por exemplo, ser fonte de óleos essenciais, modelos de controle de vetores e pragas e aditivos alimentares. São novos produtos capazes de estabelecer novos marcos conceituais e estratégias operacionais na perspectiva de uma abordagem que viabilize a melhoria da qualidade de vida da população local. Nesse sentido, a bioprospecção molecular apresenta-se como alternativa dada à pouca interferência ambiental e à baixa toxicidade para geração de produtos com alto valor agregado e que possam ser utilizados como material de partida em diferentes ramos da química fina e na geração de produtos para melhoria da saúde humana e do meio ambiente. Além disso, sabe-se que o uso tradicional de plantas medicinais é um caminho para a descoberta de compostos bioativos.

Também partindo das características já elencadas da região, esforços têm sido feitos no sentido de otimizar políticas de apoio as micro e pequenas 
empresas e aos empreendedores individuais no Litoral do Paraná.

No mês de abril de 2015, o programa de extensão Incubadora de Projetos Econômicos e Sociais, de base solidária, realizou o $\mathrm{I}^{\circ}$ Workshop de Implantação da Lei Geral dos Municípios do Paraná.

A Incubadora tem atuado como mobilizadora de agentes de desenvolvimento, micro e pequenos empresários, associações, instituições de fomento e órgãos públicos com vistas a otimizar e articular os empreendedores da região, no sentido de contribuir para o mapeamento e organização da cadeia produtiva.

Nos últimos anos, houve um crescimento significativo das MPE na região, com destaque para os microempreendedores individuais (MEI), conforme a Tabela 1.

A Tabela 2 demonstra o crescimento exponencial do microempreendedor individual (MEI), caracterizando um avanço no processo de formalização das atividades, com garantias de alguns direi- tos trabalhistas a esses empreendedores. O microempreendedor individual (MEI) é a pessoa que trabalha por conta própria e que se legaliza como pequeno empresário. Para ser um microempreendedor individual, é necessário faturar no máximo até R $\$ 60.000,00$ por ano e não ter participação em outra empresa como sócio ou titular. O MEI também pode ter um empregado contratado que receba o salário mínimo ou o piso da categoria.

$\mathrm{O}$ crescimento dos MEI na região é uma conquista, contudo fica o desafio de manter-se na atividade e ter condições de subir para outro nível, no caso o Simples. Para tanto, um dos critérios é a arrecadação.

A manutenção no mercado de trabalho e o possível crescimento na arrecadação demanda capacidade empreendedora, inovação, estudo de viabilidade econômica, formação e orientação. $\mathrm{O}$ Sebrae tem atuado nesse sentido - e a UFPR Setor Litoral, ao mediar a articulação dos MPE, tem como colaborar para a otimização dessa política pública,

TABELA 1 - Série histórica das micro e pequenas empresas no litoral do Paraná.

\begin{tabular}{|c|c|c|c|c|c|c|c|c|}
\hline Litoral & 2007 & 2008 & 2009 & 2010 & 2011 & 2012 & 2013 & 2014 \\
\hline MPEs ativas & 12.414 & 13.415 & 14.756 & 17.108 & 19.550 & 22.012 & 24.659 & 27.786 \\
\hline Mortalidade das MPEs & 198 & 588 & 260 & 251 & 212 & 205 & 191 & 176 \\
\hline $\begin{array}{l}\text { Taxa de mortalidade de } \\
\text { MPEs }\end{array}$ & $1,6 \%$ & $4,4 \%$ & $1,8 \%$ & $1,5 \%$ & $1,1 \%$ & $0,9 \%$ & $0,8 \%$ & $0,6 \%$ \\
\hline Normal & 7.072 & 7.438 & 7.780 & 8.090 & 8.332 & 8.517 & 8.704 & 8.897 \\
\hline Simples nacional & 5.191 & 5.808 & 6.660 & 7.483 & 8.272 & 8.956 & 9.659 & 10.242 \\
\hline SIMEI & 151 & 169 & 316 & 1.535 & 2.946 & 4.539 & 6.296 & 8.647 \\
\hline SIMEI/MPEs & $1,2 \%$ & $1,3 \%$ & $2,1 \%$ & $9,0 \%$ & $15,1 \%$ & $20,6 \%$ & $25,5 \%$ & $31,1 \%$ \\
\hline
\end{tabular}

FONTE: EMPRESÔMETRO (2015). 
TABELA 2 - Micro e pequenas empresas no litoral do Paraná 2007-2014 - Evolução base 100.

\begin{tabular}{|c|c|c|c|c|c|c|c|c|}
\hline \multicolumn{9}{|c|}{ Evolução, base $2007=100$} \\
\hline Litoral & 2007 & 2008 & 2009 & 2010 & 2011 & 2012 & 2013 & 2014 \\
\hline MPEs ativas & 100 & 108 & 119 & 138 & 157 & 177 & 199 & 224 \\
\hline Mortalidade das MPEs & 100 & 297 & 131 & 127 & 107 & 104 & 96 & 89 \\
\hline Regime de tributação & 100 & 108 & 119 & 138 & 157 & 177 & 199 & 224 \\
\hline Normal & 100 & 105 & 110 & 114 & 118 & 120 & 123 & 126 \\
\hline Simples nacional & 100 & 112 & 128 & 144 & 159 & 173 & 186 & 197 \\
\hline SIMEI & 100 & 112 & 209 & 1.017 & 1.951 & 3.006 & 4.170 & 5.726 \\
\hline
\end{tabular}

FONTE: EMPRESÔMETRO (2015).

tanto no sentido da capacitação dos empreendedores, quanto na assessoria para a construção de redes, parcerias e fluidez na cadeia produtiva.

Apesar dos avanços trazidos pela legislação que institui o MEI (Lei Complementar ${ }^{\circ} 128$, de 19/12/2008), a lei da terceirização recentemente aprovada pode significar perda para os trabalhadores em geral, deixando de contratá-los como celetistas e "obrigando-os" a oferecerem seus serviços como MEI. Isto reduzirá o montante recolhido para a seguridade social e os trabalhadores serão submetidos a regimes de trabalho mais instáveis e precários (Caleiro, 2015).

Outra demanda posta ao Setor Litoral refere-se ao espaço dos conselhos de políticas públicas, haja vista o desenho das políticas e a obrigatoriedade da existência dos conselhos como forma de garantir o controle social da sociedade civil. Muitos estudos têm abordado essa temática e apontado para os desafios e potencialidades desse espaço de interlocução entre Estado e sociedade civil. Muitas questões emergem dessa relação: desde a premen- te necessidade de capacitação de conselheiros, instrumentalizando-os para a compreensão dos orçamentos públicos e legislação, até o exercício da representatividade e a efetividade desse espaço na democracia participativa.

De acordo com um levantamento realizado pela secretaria executiva do conselho setorial do Setor Litoral da UFPR, o referido setor tem representação no Conselho Estadual de Desenvolvimento Rural e Agricultura Familiar (CEDRAF); no Conselho Consultivo do Parque Nacional de Saint-Hilaire Lange; no grupo de trabalho responsável pelo Termo de Ajustamento de Conduta e Plano de Regularização Fundiária do Bairro Vila Nova, em Matinhos; no Conselho de Desenvolvimento Territorial do Litoral Paranaense (COLIT); no Conselho Municipal de Saúde de Matinhos; no Conselho Municipal de Desenvolvimento Sustentável de Matinhos (CMDS) e no Fórum Municipal de Educação de Matinhos.

Essas instâncias coletivas de discussão das políticas públicas permanecem como espaços de construção de consenso, de luta por direitos, de 
disputa, de correlação de forças e de exercício da democracia. Enquanto espaços contraditórios e em disputa, "cada vez torna-se mais evidente que não é suficiente analisar os conselhos olhando apenas para as suas dinâmicas internas. É preciso recuperar o ambiente mais amplo no qual eles se situam e sobre o qual buscam incidir" (Almeida \& Tatagiba, 2012, p. 22). Nesse sentido, a temática da intersetorialidade ganha destaque, bem como os estudos que abordam as especificidades do território.

Em conversa com a direção pedagógica do Setor Litoral, apontou-se para a criação de uma comissão permanente de avaliação no setor litoral. Acredita-se que essa iniciativa seja de grande importância, principalmente para que o setor estruture uma sistemática de registro, monitoramento, articulação e avaliação das atividades desenvolvidas dentro e no entorno da Universidade. Uma dinâmica de avaliação intermitente caracteriza-se em importante estratégia de mensuração das contribuições da Universidade para o território através da tríade ensino, pesquisa e extensão.

\section{Considerações finais}

Reafirma-se as contradições e desafios do papel social da Universidade, instituição historicamente elitizada, espaço de disputa de projetos de educação e de sociedade. A análise a partir de um território possibilitou apresentar as possibilidades de ação da Universidade, considerando as peculiaridades da região litorânea do Paraná. O turismo de sol e mar, a concentração de reserva ambiental, as atividades portuária, extrativista e pesqueira, o baixo desenvolvimento econômico e a sazonalidade econômica e demográfica são alguns determinantes que compõem o mosaico desse território. Nessa perspectiva, a Universidade tem sido demandada a desenvolver ações em parceria com a comunidade e gestores públicos envolvendo as políticas: de educação, de meio ambiente, de popularização da ciência, urbana, de trabalho e emprego.

A defesa da efetivação do papel social da Universidade caracteriza-se na análise constante dos projetos, ações e opções dos sujeitos (gestores, docentes, técnicos e discentes) que constroem a instituição cotidianamente. Esse processo requer a desconstrução da cultura alienante, excludente e elitista e a construção de práticas educativas emancipatórias que possibilitem o desvelamento das determinações históricas, econômicas e políticas da realidade social. Um dos caminhos para a concretização desse desafio é o conhecimento e a articulação com os movimentos sociais, que representam as reivindicações históricas da maioria da população. Para tanto, é mister uma formação ancorada na leitura crítica da realidade social, no compromisso e no envolvimento da Universidade com as bandeiras dos trabalhadores e trabalhadoras e na clareza do projeto de educação e de Universidade defendidos. Esse processo tem um potencial revolucionário de mudança e de comprometimento com a construção de novas relações e com a crença de que outra forma de sociabilidade é possível de ser tecida.

\section{Referências}

Almeida, C.; Tatagiba, L. Os conselhos gestores sob o crivo da política: balanços e perspectivas. Serviço Social \& Sociedade, 109, 68-92, 2012 . Disponível em: $<$ http://www.scielo.br/scielo.php?script=sci_arttext\&pi$\mathrm{d}=$ S0101-66282012000100005\&lng=en\&nrm $=$ iso $>$ 
Caleiro, J. P. 6 professores e a Lei de terceirização - contra e a favor. 2015. Disponível em: <http://exame.abril.com.br/ economia/noticias/6-professores-e-a-lei-da-terceirizacao-contra-e-a-favor>. Acesso em: 25 maio 2016.

Castelo, R. As encruzilhadas da América latina e a decadência ideológica do estruturalismo latino-americano. Revista Oikos, 8(1), 71-91, 2009.

Castelo, R. O social-liberalismo brasileiro e a miséria ideológica da economia do bem-estar. In: Mota, A. E. Desenvolvimentismo e construção de hegemonia: crescimento econômico e reprodução da desigualdade. São Paulo: Editora Cortez, p. 46-77, 2012.

Castelo, R. O canto da sereia: social- liberalismo, novo desenvolvimentismo e nova supremacia burguesa no capitalismo dependente brasileiro. Em Pauta, 31(11), 119-138, 2013.

Coutinho, C. N. A hegemonia da pequena política. In: Oliveira, F.; Braga, R.; Rizek, C. A hegemonia às avessas: economia, política e cultura na era da servidão financeira. São Paulo: Editora Boitempo, p.29-43, 2010.

Cultimar. Apresentação. Disponível em: http://cultimar.org. br/site/. Acesso em: 10 maio de 2016.

Eagleton, T. Ideologia: uma introdução. São Paulo: Ed. UNESP/ Ed. Boitempo,1997.

EMPRESÔMETRO. Estatísticas, 2015. Disponível em: http://empresometro.cnc.org.br/Estatisticas. Acesso em: fev. 2015.

Esteves, C. J. O. Vulnerabilidade socioambiental na área de ocupação contínua do litoral do Paraná, Curitiba, Tese (Doutorado em Geografia) - UFPR, 2011.

Góes, L. M. Conservação e grandes empreendimentos de infraestrutura no litoral do Paraná: a ferrovia Lapa-Paranaguá. Curitiba, Dissertação (Mestrado Meio Ambiente e Desenvolvimento) - UFPR, 2014.

Gramsci, A. Cadernos do Cárcere. Rio de Janeiro: Civilização Brasileira, 1999.

Gramsci, A. Cadernos do Cárcere. Rio de Janeiro: Civilização Brasileira, 2002.

Gramsci, A. Cadernos do Cárcere. Rio de Janeiro: Civilização Brasileira, 2006.
Koga, D. Medida de cidades: entre territórios de vida e territórios vividos. São Paulo: Cortez, 2011.

LABMÓVEL. Laboratório Móvel de Educação Científica da UFPR Litoral, 2014 (mimeo).

Leher, R. Uma penetrante perspectiva teórica para compreender como os dominantes dominam. In: Neves, L. M.W. (Org). Direita para o social e esquerda para o capital. São Paulo: Editora Xamã, p. 11-18, 2010.

Marçal, J. P. Politica de ação afirmativa na Universidade Federal do Paraná e a formação de intelectuais negros (as). Curitiba, Dissertação (Mestrado em Educação) - UFPR, 2011.

Martins, A. S.; Neves, L.M.W. A nova pedagogia da hegemonia e a formação/atuação de seus intelectuais orgânicos. In: Neves, L. M. W. (Org.). Direita para o social e esquerda para o capital. São Paulo: Editora Xamã, p. 23-38, 2010.

Pastorini, A. Quem mexe os fios das políticas sociais? Avanços e limites da categoria concessão-conquista. Serviço Social \& Sociedade, 18(53), 80-101, 1997.

Pierri, N. A ocupação e o uso do solo no litoral paranaense: condicionantes, conflitos e tendências. Desenvolvimento e Meio Ambiente, 13, 137-167, 2006.

Saraiva, E. Introdução a teoria da política pública. In: Saraiva, E.; Ferrarezi, E. (Orgs). Políticas públicas. Brasília: Editora ENAP, p. 07-42, 2006.

Silva, E. L. P.; Wanderley, M. B.; Conserva, M. S. Proteção social e território na pesca artesanal do litoral paraibano. Serviço Social \& Sociedade, 117, 169-188, 2014.

Simionatto, I. Intelectualidade, política e produção do conhecimento: desafios ao Serviço Social. Serviço Social \& Sociedade, 117, 7-21, 2014.

Tonet, I. Atividades educativas emancipatórias. Práxis Educativa, 9(1), 9-23, 2014.

Vieira, E. Os direitos e a política social. 2. ed. São Paulo: Cortez, 2007.

Zhouri, A.; Laschefski, K. Desenvolvimento e conflitos ambientais. Belo Horizonte: Ed. UFMG, 2010. 